\title{
Use of Dance to Spread Propaganda during the Sino-Japanese War
}

\author{
By Yukiyo Hoshino*
}

This study examines how the Japanese used dance to spread propaganda during the Sino-Japanese War in the 1940s. It focuses on three dancers: Choe Seung-hui, Tsai Jui-yueh, and Lee Tsia-oe. All three were natives of either Korea or Taiwan, which were occupied by the Japanese. Both in Japan and in Japanese-occupied portions of China, Japanese dance companies entertained the Japanese army and artisans working in munitions factories. Colonized Taiwanese and Korean dancers participated in these dance companies, giving them a means of passing on their own ethnic cultures, even though they were performing on behalf of the Japanese empire. After the war, these dancers helped to popularize modern dance in their respective countries. However, during the political transitions of the Korean War and the White Terror in Taiwan, some dancers' activity was suppressed because of their prior cooperation with Japanese imperialism.

\section{Introduction}

In July 1937, the Japanese launched a full-scale invasion of China and expanded their empire to Manchuria, Shanghai, Hong Kong, and countries in the South Pacific. During the years of the ensuing Sino-Japanese War, from 1937 to 1945, mainland China was divided into three areas: the liberated region, the Japanese-occupied area, and the area ruled by the National Party. In each area, both combatants in the war used propaganda to influence peoples' opinions. Although some historical records on this period exist in mainland China, few researchers have referred to them, assuming that they were not primarily related to the history of the Communist Party. However, an investigation of these historical documents and interviews with older dancers have provided the results presented in this study.

In the National Party-ruled area, Chinese dancers organized small dance companies and barnstormed, presenting concerts sponsored by both the National Party and the Communist Party. The programs generally depicted the crimes of the Japanese army or the courageous resistance of the Chinese people. ${ }^{1}$ Meanwhile, in the enemy-occupied region, Japanese dancers organized dance companies and entertained the Japanese army and artisans

\footnotetext{
* Professor, Nagoya University, Japan.

1. Y. Hoshino. "Konichi Undo ni Okeru Byoka Tai Airen: Chin Yuujin, So Keirei to no Kakawari wo Chuxin ni" ["Dai Ailian in Anti-Japanese Demonstrations: Focusing on Her Relationships with Eugene Chen and Soong Ching-Ling"], Tohogaku. 124 (2012): 62-63; Y. Hoshino, "Konichi Buyo to Yikusai Gakko no Setten: To Kochi Tai Airen Go Gyoho no Gassaku" ["Anti-Japanese Propaganda Dance in the School for Nourishing Talent: Collaborations of Tao Xingzhi, Tai Ailian, and Wu Xiaobang"], in Takakuteki Shiten kara Mita Nicchu Senso, ed. Tsuyoshi Baba (Fukuoka: Shukosha, 2015), 318-319, 325-327.
} 
working in munitions factories. In addition, Japanese people spread propaganda through literature, music, plays, and dance to justify the invasion.

This study examines how colonial dancers participated in spreading propaganda within the Japanese-occupied area during the years of the SinoJapanese War. Most studies regarding entertainment for Japanese soldiers have overlooked the fact that the entertainers were colonial subjects. ${ }^{2}$ As Japanesesponsored dance troupes traveled through occupied areas and in Japan to entertain soldiers and laborers, Choe Seung-hui, Tsai Jui-yueh, and Lee Tsia-oe participated as Japanese, even though they were natives of colonized lands. From the perspective of comparative cultural studies, Faye Kleeman (2014) has already analyzed the activities of Choe and Tsai. This study adds information on Lee and describes the experiences of all three under the Japanese occupation. Furthermore, it identifies their contributions to establishing modern dance in their own countries and examines the political repression that they experienced during the period of decolonization.

\section{Choe Seung-hui: One of the Most Brilliant Disciples of Baku Ishii}

I have selected these female dancers because all three studied under Baku Ishii (1886-1962), a pioneer of Japanese modern dance. Ishii studied classical ballet under Giovanni Vittorio Rossi (1867-?), an Italian choreographer who taught at the Imperial Theatre in Tokyo, and later began to cultivate a modern dance style of his own. He went to Europe to hold recitals, achieving significant popularity during the 1920s. After the Sino-Japanese War began, the military authorities requested that Ishii entertained the Japanese troops, and that he traveled around the northern cities of mainland China, Shanghai, Taiwan, and Vietnam with some dancers who had graduated from or were studying at the Ishii Dance School in Tokyo.

Choe Seung-hui was a top dancer among Ishii's students in the late 1920s, who earned a global reputation during the war. $^{3}$ She began studying dance at the Ishii School after her brother expressed appreciation for a performance by Ishii in Seoul in 1926. Ishii advised her to incorporate Korean ethnic dance into modern dance. She held her first solo recital in Tokyo in 1934 and received enthusiastic applause. Furthermore, a film titled A Dancing Girl in the Korean Peninsula, which featured Choe, was produced in 1936. She traveled to the United States and Europe to hold recitals and received unprecedented praise.

Because Choe had acquired significant success in the West, Japanese critics thought that she should represent "Five Races under One Union," which was a national motto in Manchuria. For instance, a Japanese critic named

2. M. Misako, Rikugunsyo Haken Gokuhi Jugun Buyodan [A Sacred Dance Company Dispatched by the Department of Japanese Army to the Front] (Tokyo: Seiunsha, 1995), 101186.

3. F.Y. Kleeman, In Transit: the Formation of the Colonial East Asian Cultural Sphere (Honolulu, HI: University of Hawaii Press, 2014), 199-206. 
Natsuya Mitsuyoshi stated the following regarding Choe's recital in Shanghai in 1943:

Now it is a remarkable assignment for us that Asian people who are devoted to establishing a Great Asia. Thus, we have great hope for the success of the first concert of Choe Seung-hui in the Middle of China, and that the concert will impress the Chinese people. ${ }^{4}$

Mitsuyoshi's comment reflected his expectation that Choe would help to justify a Great Asia under Japanese rule. Choe appeared as a Japanese dancer in her performances, but she privately sympathized with the Korean resistance. Katsue Yuasa, a writer and a close friend of Choe and her husband, happened to see Choe dance for Japanese army members stationed in Seoul in 1945, and he described his interaction with her as follows:

"I was fascinated by the beauty of her dance for a while, and then I noticed that the music was Pomi Wanne.

'It's Pomi Wanne, isn't it?' I said.

'Yes, it is!' Choe Seung-hui said, turning her face toward me with a grin. ... Pomi Wanne literally means the spring has come; the Korean people, however, sing the song with the hope that the springtime would come for them."

In this way, through her dance, Choe appealed in a significant way to the Korean ethnic culture. After the end of the war, she was severely criticized in North Korea for having accepted the dance culture of the Japanese empire. Specific details regarding her death in North Korea are unavailable.

\section{Dancing at Military Factories: Tsai Jui-yueh}

Tsai Jui-yueh admired Ishii's performance in Tainan and went to Tokyo by herself in 1937. When Tsai began studying dance at the Ishii Dance School, dance concerts had already been prohibited as superficial activities. Thus, the only way to dance was to go to the front lines or to a military factory to entertain soldiers or laborers. After two years, Tsai was favorably impressed by the performance of Midori Ishii, a former student of Baku who had set up her own dance company, and so she became part of Midori's troupe.

From 1941 to 1945, Tsai traveled around mainland China and Japan as a member of Midori's company. Initially, they went to Gaoxiong in Taiwan and to Burma to entertain the Japanese army on trips sponsored by the Japan

4. N. Mitsuyoshi, "Sai Shoki no Buyo" ["The Dance of Choe Seung-hui"], Tairiku Shinpo, September 29, 1943.

5. K. Yuasa, "Maihime no Kioku" ["Choe Seung-hui in My Memory"], in Tsushima, ed. Katsue Yuasa, 202-203.Tokyo: Tokyo Shoten, 1952. 
Broadcasting Corporation. ${ }^{6}$ The soldiers never failed to make the dancers feel welcome. In Japan, the dancers visited virtually every prefecture in the Japanese archipelago and danced for workers at iron factories, oil and fat factories, and spinning and weaving operations, and sometimes for mothers as well. $^{7}$ Their Japanese tour was sponsored by the Mainichi Newspapers Company and the Home Front Apprenticeship Association, among others. They danced to military songs such as "If I Go Far Away to the Sea," "Shooting Goes On", and "The Patriotic March", along with Japanese ethnic songs.

After Japan's defeat, Tsai returned to decolonized Taiwan, but hard times were awaiting her. At the beginning of the White Terror in Taiwan, her husband, Lei Shi-yu, was arrested and forcibly deported back to Hong Kong, and then Tsai was also arrested. The reason was ostensibly that she was suspected of having engaged in espionage for the Communist Party; however, after the February 28 Incident in Taipei, the people being arrested in Taiwan were intellectuals who had received higher education under Japanese rule. Thus, it is likely that Tsai was arrested because she had studied dance in Japan and been involved in spreading "imperialistic" dance. During her imprisonment, Tsai was often forced to entertain high officials in the Chinese Nationalist Party. After three years, she was finally released from prison and went on to establish the Tsai Jui-yueh Dance Art Research Center and to teach many notable dancers.

\section{Lee Tsia-Oe of Taiwan}

Lee Tsia-Oe (1926- ) enrolled in the Ishii Dance School in 1939. At that time, Zai Pei-huo (1889-1983), the leader of the Taiwanese new cultural movement, was encouraging Taiwanese youth to pursue higher education in Japan to establish Taiwanese culture there on their own initiative. Therefore, he took Lee, whose father was his good friend, to Tokyo.

Baku Ishii discovered Lee's talent and selected her to participate in dance competitions. She won the first prize for her solo performance in the dance competition held by the Miyako Newspaper Company in 1941, the second prize for a group dance in the same competition the following year, and the first prize for a group dance in another competition. Lee recollected having been cheered by the audience as "Lee Tsia-Oe of Taiwan". ${ }^{8}$ After that, Baku Ishii placed this description of her in a brochure on his company: "Lee Tsia-Oe, 17 years old this year, was born in Taiwan. She is a promising young dancer who earned first and second prizes in contests in the east metropolis [Tokyo]

6. M. Ishii, Yoku Ikiru to ha Yoku Odoru koto [To Live Well is to Dance Well] (Tokyo: Soshi-Sha, 2004), 55-60.

7. I. Orita, Handwritten Documents, 1941-1945, in Tsai Jui-yueh Dance Research Institute's Possession.

8. Y. Hoshino and T. Yang, "Fei-wu Ren-sheng: Taiwan Gendai Buyoka Li Saiga shi Interview" ["Dancing Life: An Interview with a Taiwanese Contemporary Dance Artist Lee Tsia-Oe"], Studies in Language and Culture 35, no. 2 (2014): 73. 
". 9 It seems that Ishii wanted to allow Lee to represent Taiwan through dance while Choe represented Korean ethnic dance. Fortunately, Tsai returned to Taiwan in 1943, before Japan's defeat in the war.

Lee also toured with Ishii's dance troupe to entertain soldiers. In mainland China, the dancers traveled around Harbin, Mudanjiang, Dalian, and Changchun, and they then went to Hanoi. Lee said that she was very popular among the Japanese troops stationed in these locations, even though she was introduced as "Lee Tsia-Oe of Taiwan". The dancers performed to military songs such as "If I Go Far Away to the Sea", Japanese popular songs such as "The Moon over the Ruined Castle" and "Oriental Waltz", and many more.

Soon after returning to Taiwan, Lee married and stopped dancing until she was invited by the Taiwanese government to become a teacher of modern and ethnic dance as part of the Taiwanese ethnic culture movement of the late 1940s. In contrast to Tsai's experience, it appears that this break from dancing helped Lee escape from becoming embroiled in the oppression during the White Terror era. She established the Lee Tsia-Oe Dance School in Gaoxiong in 1954, choreographed for many dance repertories, incorporated Taiwanese ethnic dance into modern dance, and continues to train modern dance instructors and her successors even today.

Lee's career as a dancer in Japan was exceptional, but it was also relatively short. Thus, she could more easily shed the unwanted image of having been a cultural symbol for Japan's vision of a Great Asia.

\section{Conclusion}

The three remarkable dancers featured in this study were products of the early years of modern dance in Japan. All of them studied dance in Japan due to their desire to pursue excellence as artists. During the Sino-Japanese War, however, dance was not simply an artistic performance. Because dance is a physical and expressive performance not limited by the boundaries of language or dialect, it can become a convenient carrier of propaganda.

As for their dance careers under the Japanese occupation, Choe Seung-hui began at age 16 and continued until her mid-30s, Tsai Jui-yueh performed from age 16 to her mid-20s, and Lee Tsia-oe was a teenager. Therefore, Choe saw her best days as a dancer during wartime, Tsai was maturing as a maturing dancer, and Lee had just graduated from dance school. The length of each dancer's carrier under Japanese imperialism influenced the treatment that they subsequently received from authorities in their home countries.

Korean and Taiwanese dancers' performances were a very effective way of representing the aims of Japanese imperialism. The oppression later experienced by Choe and Tsai bears witness to this fact. Once they had been released from Japanese Imperialism, their dancing bodies fell into the hands of new, sometimes even more oppressive authorities.

9. B. Ishii, "A brochure on the 30 memorial concert of Ishii Baku company", in Fei Wu Rensheng, ed. Tsai-oe Lee, 39. Gaoxiong: Cultural Community of Gaoxiong, 2010. 


\section{Acknowledgments}

Research for this article was supported in part by Grants-in-Aid for Scientific Research of the Ministry of Education, Culture, Sports, Science and Technology of Japan. The authors would like to thank Enago (www. enago.jp) for the English language review.

\section{Bibliography}

Kleeman, F. Y. In Transit: the Formation of the Colonial East Asian Cultural Sphere. Honolulu, HI: University of Hawaii Press, 2014.

Hoshino, Y. "Konichi Undo ni Okeru Byoka Tai Airen: Chin Yuujin, So Keirei to no Kakawari wo Chuxin ni" ["Dai Ailian in Anti-Japanese Demonstrations: Focusing on Her Relationships with Eugene Chen and Soong Ching-Ling"]. Tohogaku, 124, (2012): 54-70.

Hoshino, Y. "Konichi Buyo to Yikusai Gakko no Setten: To Kochi Tai Airen Go Gyoho no Gassaku" ["Anti-Japanese Propaganda Dance in the School for Nourishing Talent: Collaborations of Tao Xingzhi, Tai Ailian, and Wu Xiaobang"]. In Takakuteki Shiten kara Mita Nicchu Senso, edited by Tsuyoshi Baba, 313-336. Fukuoka: Shukosha, 2015.

Hoshino Y. and T. Yang. "Fei-wu Ren-sheng: Taiwan Gendai Buyoka Li Saiga shi Intervie" ["Dancing Life: An Interview with a Taiwanese Contemporary Dance Artist Lee Tsia-Oe"]. Studies in Language and Culture 35, no.2 (2014): 69-82.

Ishii, M. Yoku Ikiru to ha Yoku Odoru koto [To Live Well is to Dance Well]. Tokyo: Soshi-Sha, 2004.

Mitsuyoshi, N. "Sai Shoki no Buyo" ["The Dance of Choe Seung-hui"]. Tairiku Shinpo, Sep.29, 1943.

Misako, M. Rikugunsyo Haken Gokuhi Jugun Buyodan [A Sacred Dance Company Dispatched by the Department of Japanese Army to the front].Tokyo: Seiunsha, 1995.

Lee, T- O. Fei Wu Rensheng [Dancing Life]. Gaoxiong: The Cultural Community of Gaoxiong, 2010.

Orita, I. Handwritten Documents, 1941-1945. In MoProphet of Taiwanese Dance: An Oral History by Tsai Jui-yueh, Edited by Jui-yueh Tsai. Taipei: Taiwan Cultural Council, 1999.

Yuasa, K. "Maihime no Kioku" ["Choe Seung-hui in My Memory"]. In Tsushim, Edited by Yuasa Katsue, 191-207. Tokyo: Tokyo Shoten, 1952. 